\title{
Improvisation as a Creative Dialogue
}

\author{
Oded Ben-Tal Music Department, Kingston University, London \\ o.ben-tal@kingston.ac.uk \\ Caroline Wilkins Music Department Brunel University \\ caroline.wilkins@brunel.ac.uk
}

\section{Keywords: sound theater, interactive electronics, machine listening}

\section{Abstract}

Our paper will describe the creative process of Zaum: Beyond Mind an interactive sound theater performance, and examine the role of improvisation in shaping the piece. Zaum is a modular performance for voice, bandoneon, piano and electronics- integrating both live interactive elements and fixed sounds - with lighting, and video projection. While the creative process included traditional modes of composition, a significant aspect in melding the contribution of two composers each with a different approach to composition - shares important attributes with improvisation. It is to do with creative listening, adjusting our individual contribution in response to changing contexts, and developing a shared sense of musical pacing and narrative. Improvisation also played a significant role in developing the technological, interactive elements of the piece with a co-evolution of the programming and the performance over a lengthy process of exploration and adjustments. This process, therefore, entails multiple dialogues, musical as well as verbal, between us as a duo and between us and our instruments. On the way we discovered that analytical reflection, despite its connotations of cerebral processes popularly portrayed as in opposition to the spontaneity required in improvisation, played a crucial role in the shaping of the piece.

Short video excerpts from performances available at:

http://fass.kingston.ac.uk/research/music/areas/intermedia/zaum/

\section{Introduction}

In its current form, a performance of Zaum: Beyond Mind opens with a bare stage. Soft light illuminates two small tables. A laptop is placed on one and a bandoneon on the other. Four speakers are located at the corners of the room. 


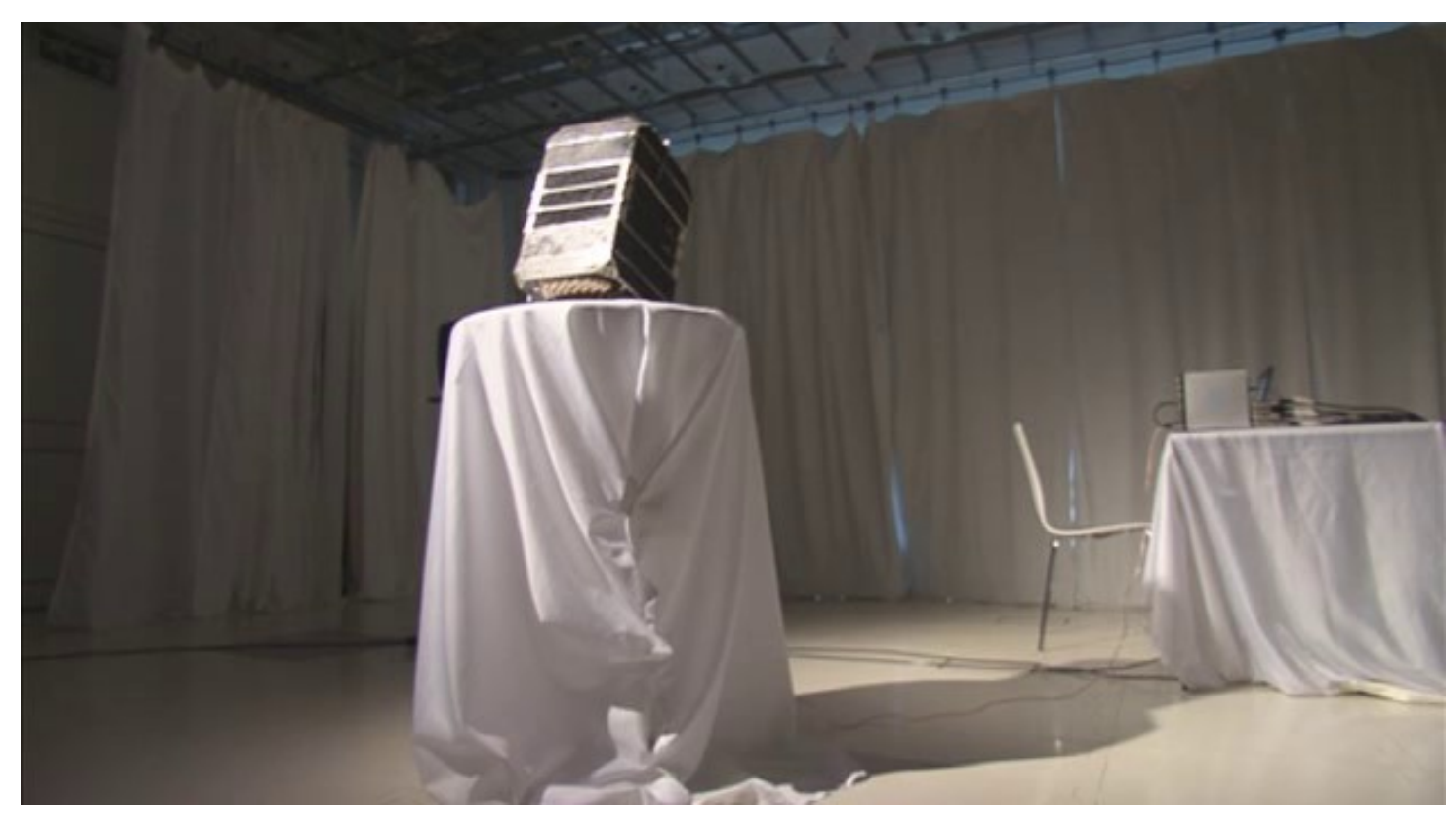

Illustration 1: Stage-set, Zaum: Beyond Mind, Image: Amna Hafeetz.

The first sounds are vocal utterances from Caroline - whistles, whispers, laughter but she is not visible to the audience. The voice is amplified with some modulation but this electronic counterpart is mixed very low. She is the first to enter the stage, still vocalising, wearing a golden gown and a wireless microphone on her head. She approaches the laptop and presses the keyboard to trigger descending glissando electronic sounds. She moves to the front of the stage area where another spotlight illuminates her. Oded enters behind her back, walking slowly to the laptop.

Let's pause here for a second and consider some of the elements described above. The first important aspect is the audio-visual -we are concerned in this piece with the notion of Sound theater (Heile 2006, Vear 2009), which aims to redress the balance between the visual and aural components prevalent in many multimedia performances, drawing attention to the phenomenological qualities of sound, music 
and theater. A theater of sound also aims to re-evaluate the relation between score and performance inherited from music theater practice in the light of new technological developments over the last twenty years. Essentially, it is an experimental interdisciplinary concept that combines field recordings, live computer music, mental imagery evoked from sound, and a multimedia theater performance environment.

These theatrics of sound start with the stage setting - creating a visual equivalent between the bandoneon and the laptop. As the first sounds emerge, their acoustic source hidden and electronically transformed, Caroline enters, 'plays' the computer and moves to the front of the stage area; we are signalling to the audience the importance of location, space, and action in (our) musical performance. This paper will highlight how ideas about sound theater shape our work process and our performances.

Another important element is our approach to composition with interactive electronic components. In most cases where a performer (or performers) on stage interact with a computer, it is located within the audience and not on stage. This reflects a division of labour practice - the composer's work was mostly finished when the rehearsal process began. Perhaps some small changes happened in rehearsal in order to render the composer's ideas more effective. The concert is the performer's time in the spotlight and the composer becomes the assistant. As this paper will show, our approach shares some attributes with this process but is also very different in important respects.

Finally, "In its current form" refers to the fact that this is an evolving project. We continue to develop new ideas and refine elements we currently have. We are also adapting our performance to each individual context (the space, the audience, the program). The role of improvisation, both as part of the performance as well as in the process of melding our creativity together to shape the piece, is crucial in arriving at such an adaptable format.

We consider the performance as an interplay between three participants: (1) Caroline performing on the bandoneon, piano and vocally, and (2) Oded who is operating the (3) computer which acts as a semi-autonomous agent. The live sounds from Caroline are fed into the computer through two microphones - a contact microphone mounted on the bandoneon and a wireless vocal microphone allowing her the freedom to move about the space and use visual gestures. Musical material, the dramaturgy of the piece, and the software created were all shaped by a give-and-take relationship between us as we explored different ideas and combinations, listened and responded to each other, and engaged in reflection and analysis of the emerging composition.

In this paper we will examine the role of improvisation in the creation and performance of our piece from different angles. First we will discuss the technology we are using, it's development process, and the evolving interplay between the acoustic and electronic sounds. Next we will examine improvisation as practice in the piece and how our own approach and experience with composition and improvisation shapes the piece. We will then consider the dramaturgy of the piece in relation to improvisation, and finally, examine how analytic approaches support our improvisation practice.

\section{Improvisation and Technology}


Oded is using Pure-Data $\left(\mathrm{Pd}^{1}\right)$ to program the live interactive electronics in the piece. Audio input from Caroline - through a contact microphone attached to the bandoneon and a wireless vocal microphone - is analysed to identify salient musical features and generate responses that integrate with her unique performance style. This can be described as ad hoc machine listening. Unlike more systematic approaches to machine listening (e.g. Collins 2005) we do not aim for a generalised system, instead opting for narrowly tailored elements. Examples of musical features the Pd patch is programmed to identify include:

- Whistling.

- Voiceless noises (such as 's' 'sh' 'f')

- Short melodic contours sung legato.

- Sustained long notes on the bandoneon.

- Percussive sound on the body of the bandoneon.

Arriving at this stage was a long process that began in the studio where we recorded a variety of sounds; these included very short simple ones (on the bandoneon: low sound, high sounds, key clicks, etc.; from the voice: spoken words, whistling, Sprechstimme, etc.) and also more extended vocal / instrumental improvisations. Oded programmed Pd patches that could identify some of the types of sounds or textures Caroline performs and generate 'appropriate' electronic responses to them.

The process continued with periodic meetings in the studio where Caroline would perform together with the patch in its current state, learning about the programmed interaction and exploring the evolving sound world. Because Pd was programmed to respond to specific inputs we would often hear unexpected sounds resulting from feeding the patch sonic inputs that varied considerably from the test sounds used when programming them, including very interesting conjunctions, leading to further adjustments to the patches. In this regard the creative process was similar to an improvisation albeit in slow-motion where we each adjusted our contribution in response to the other.

The live electronic responses generated through Pd aim to integrate sonically and musically with Caroline's performance. In a few cases the system uses the incoming signal. For example when the system identifies whistling - a high, fairly stable pitch in a limited register - the response feeds these into very short variable length delay lines resulting in small glissandi ornamentations of the sounds. But most of the responses are generated rather then processed. For example when she plays long sustained notes on the bandoneon the system begins adding selected harmonics, in random order, over the identified note. These integrate well with the rich spectrum of the instrument. In other cases some of the recordings we made in the studio are used as source material for the electronic sounds. Thus, short bursts of transformed bandoneon clusters respond to vocalisations, with the decay of the sung utterance shaping the processing applied.

During the performance Oded is making only limited changes to the system's operation in order not to hinder the programmed interaction between Caroline and the machine, a similar approach to that taken by Harrald (2007). This means that during the performance she is improvising with the machine more than with him. In that respect this approach to programming live electronics is similar to machine improvisation (for example Hsu 2010, Young 2007). But unlike those, the program 
was not developed with an improvisation strategy in mind. Rather it is a collection of modules that independently respond to specific stimuli. Any "personality" or strategy identified (by Caroline or the audience) in the machine is an emergent property of the creative process. The system is tailored very specifically to Caroline's performance style rather then an improvising agent that could adapt to different situations. Nevertheless the result does address two interesting challenges raised by Van Noort (2009) namely:

(1) the system is able to produce novel outputs influenced by the performer's input in fact Oded was sometimes surprised by the outputs generated by the system in rehearsal as opposed to the tests using pre-recorded material.

(2) it responds to inputs of varying durations, from notes to short phrases, leading to interaction at different musical levels.

Two important attributes that these independent modules share are:

(1) selective response - an output is generated only in response to selected inputs from Caroline, and

(2) the interaction goes through a symbolic level of representation, not just at the signal level. To illustrate why this is significant, consider the simple case where the live processing applied to the input is a 2-second delay. When this is applied in the signal level we would describe it as an echo, but when the same processing is applied in the symbolic level, we call it a canon ${ }^{2}$. Thus the difference between delay in the symbolic and signal level is one of perceived agency, even though this agency may be wholly illusory. Similarly, with other, more complex types of electronic responses, we analyse the incoming signal to identify features (at a symbolic level even if not simple MIDI-type events) to allow for more multiplicity in the relationship between Caroline's performance and the electronic responses.

Another layer of electronic sound used in the piece is created by fixed sound-files triggered manually. These are based on some of the material - both voice and bandoneon - that we recorded in the process. Some underwent significant transformations (such as granulation, convolution, and filtering) while others are almost unchanged. The first one, as described above, is triggered by Caroline soon after entering the stage and belongs to the former type, based on bandoneon recordings pitch-shifted and granulated. Further on into the performance, Oded is triggering (following her auditory and visual cues) ghostly renditions of Caroline's reading of the Zaum poetry which informs the piece. These form a disembodied choir speaking her re-arrangement of the text, repeating words and phrases that are spread throughout the quadrophonic speaker setup in a spatial dialogue both with each other and with the performer on stage.

Having outlined the parameters of our improvisational tools, we now examine the actual practice of improvisation in relation to the work Zaum: Beyond Mind.

\section{'release what's there' ${ }^{3}$}

In his vital statement on improvisation, David Tudor encapsulates an approach to improvisation that recognises the inbuilt potential of an instrument, whether electronic or acoustic. He goes on to say, "the object [instrument] should teach you what it wants to hear," (2004) suggesting that we step back from technical proficiency or pre-determined knowledge and enter into a state of amnesia by allowing the 
unexpected to manifest itself. This is perhaps what he meant by "new virtuosity," the key word here being "release," indicating that sonic energy is already condensed within the history and making of this instrument. Thus, the contemporary practice of improvisation often contends with our traditionally-oriented academic training, unless we are able to render the two mutually compatible. However, this challenge lies at the heart of Caroline's fascination for the bandoneon -- namely to re-discover it by means other than the conventional training offered by traditional playing methods. She devised a system of mapping the complicated key systems on either side of the instrument, which are not arranged in any logical pitch order and produce a different sound according to whether the bellows are drawn or pushed. This sets up a relative sense of pitch combinations that the fingers locate according to their patterns and distances on each keyboard. Thus gestural and textural aspects become the main focus rather then pitch structures. This very much fits in with Oded's approach to the electronics, which also foregrounds audio gestures and sonic densities. This also harkens back to Zaum poetry and its influence down to the present, namely, shifting the focus of artistic expression into a peripheral aspect (the sound of words rather then their meaning; gesture at the expense of harmony) in order to renew the art form. It still remains possible to notate improvisational sketches by means of an open-stave system where pitch ranges are defined according to their vertical space on the page. 
Illustration 2: Zaum: Beyond Mind, score excerpt showing notation of bandoneon.

Intrinsic to the mechanism of the instrument is the time it takes to react to the pull/push of its bellows, the air stream carrying the sound from reeds opening and shutting inside the casing. There is a certain attack/delay effect, a link with the human in-breath/out-breath, an "effort" of difficult breathing. The instrument creates and 
discovers space through its breath. It inspires, blows in, breathes, being essentially a tactile instrument, with two resounding boxes to the left and right of a long bellows. It is anthropomorphic, functioning only by means of air like a human being, and producing a raw, reedy timbre. The player and instrument become one in a mixture of organic form and object, constantly changing roles. Their relationship is intimate.

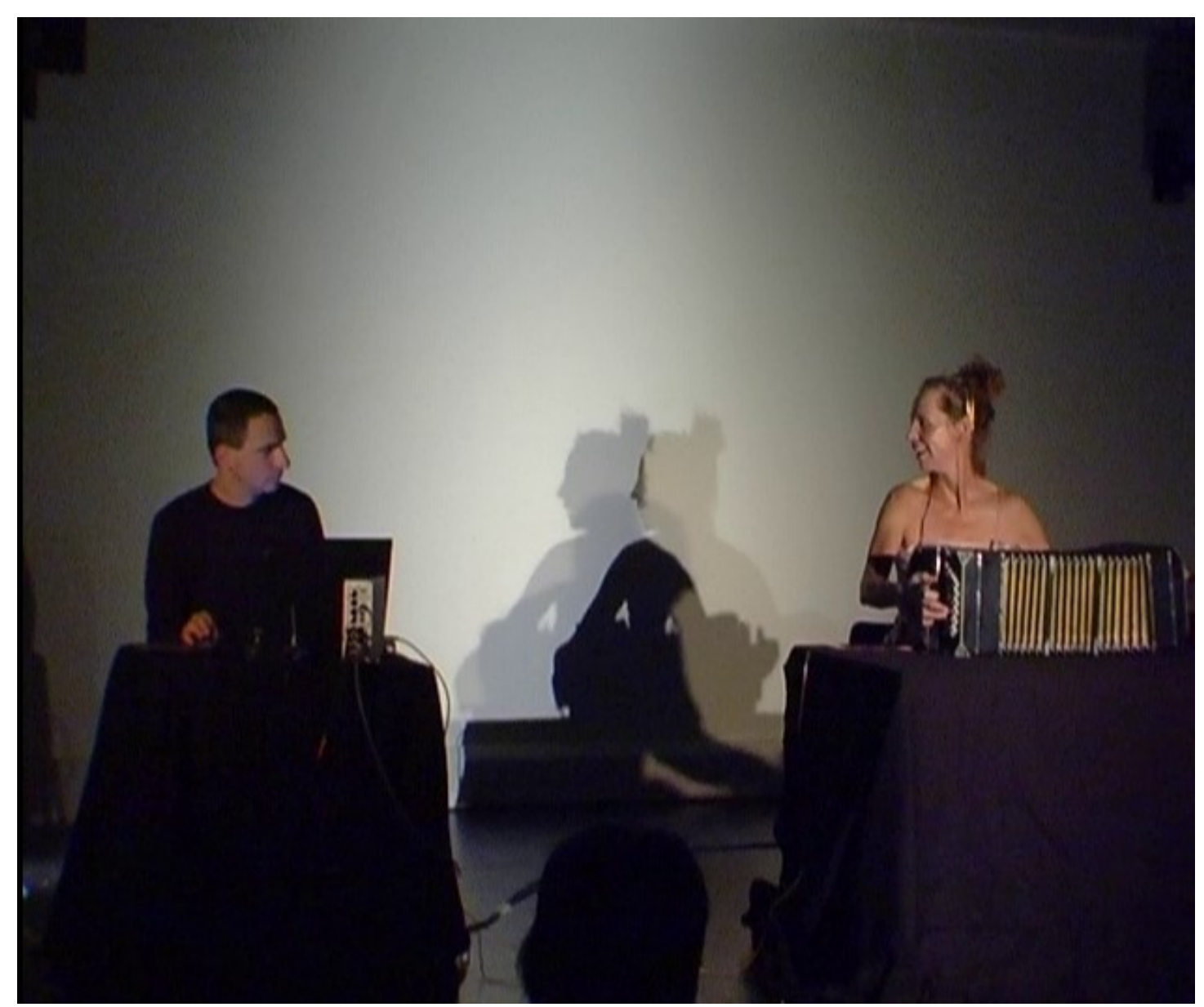

Illustration 3: Zaum: Beyond mind. Performance DRHA conference, Brunel University, 2010, Photo: Neil Graveney.

Vocal improvisation developed very much from listening to the timbres of the bandoneon, such as air sounds, humming, and whistling. However, a decisive influence was the choice of sound poetry as a basis for vocal exploration: zaum. Coined by Russian poet Khlebnikov, "zaum" means "beyond mind." It is used to describe experiments in sound symbolism and linguistic creation stemming from Russian Futurist poets of the 1900's such as Khlebnikov and Kruchonykh . This poetry, in particular by Alexei Kruchonykh , provides the basis for much of the vocal material used in the performance. 
Zaum in Tiflis,

1917-1921:

KRUCHONYKH

\author{
pale are all \\ the lands \\ and red \\ the noses \\ i alone am sev- \\ ere \\ and black \\ like \\ a plaster
}

thing fragment

mindfragment

fragment

speech-

Let -

Terfragmen

t

pleasing the plague

of her husband Lazhila
lived on the Zhil
crops of banter
Great

Zaum: The Transrational poetry of Russian Futurism.(trans. Gerald Janacek) San Diego State University Press, 1996. re-printed with permission from the publisher. 
There is a direct historical link between the trans-rational language or 'wordsin-freedom' of zaum and the early foundations of electronic music, namely their insistence on sound and noise as liberating factors that challenged the aesthetic confines of words and music. Employing all manner of vocal styles including Sprechstimme, lyric, dramatic, Belcanto, and jazz, Caroline deconstructs the words into phonemes, re-arranges their order at random and collides one expressive moment with another in a series of contrasting interjections.

Linking the vocal and instrumental aspects of the performance is also an important component in the design of the electronic sounds. Some of the live responses attempt to marry the two quite directly, for example by using convolution between the vocal input and bandoneon sound stored on the computer to create a vocalised-bandoneon. Others use sounds common to both, such as filtered noise bands which both can produce easily. Some of the fixed sound-files triggered during the performance are built from processing both instrumental and vocal recording to achieve a blended sound that is transformed yet retains sonic links to its acoustic origins. It is also noticeable that the audience hears bandoneon sounds, triggered in response to Caroline's voice, for an extended section at the beginning of the performance before the instrument actually emits its first acoustic sound later on in the piece.

At this point it is useful to examine what kind of elements are at play during a live performance of interactive improvisation with electronics. Firstly, the improviser is faced with multiple tasks that all take place within fractions of a second, and thus call for another mode of functioning that "expands according to the parameters of a cognitive system, extending embodied awareness by means of electronic prosthesis" (Hutchins, 1995: 291). Understanding this process starts with the concept of sensitization, meaning that the performer's levels of observing, listening and response are finely tuned in their flexibility towards a sonic or visual input. These operations have as much to do with a sense of play as with a strong sense of timing and control, the latter an important element in terms of the performer being able to monitor the aural balance between live and electronic sound. The second important concept is that of 'gestural nuance'- meaning the interpretive subtleties which bring an inherently human aspect to the relationship and include elements such as rubato, phrasing, dynamics and articulation - which stems from Guy Garnett (2001: 21-33) Sensitization and gestural nuance, together, allow the performer to develop what Simon Emmerson terms “control intimacy” (2007:96).

Secondly, freed from having to produce a continuous horizontal line of live sound, the improviser can concentrate on momentary interjections with the electronics, the two building aggregates of vertical intensity as their combined durations overlap. Or the live voice / bandoneon can be extended electronically in terms of duration, timbre or dynamic -- this beyond human technical capabilities -and allow the performer time to explore other visually expressive means such as gesture or movement in this improvisatory space.

Finally, the process of responding to generated sound is both fascinating and highly complex, involving a constant flow of dialogue that rebounds from the electronic response. The nature of interaction is so fast (and spontaneous on the part of the live improviser) that the sonic transformations themselves lead to new, surprising areas, indicating a third element that goes beyond the determination of 
either human protagonist: "Interaction is built on the belief that to remove the hand of the artist is to invite unexpected results” (LaBelle 2007:289).

In her own reaction to and interaction with the electronics in Zaum: Beyond Mind Caroline combines an approach of control with that of openness. Having worked extensively with the Pd patch during rehearsal sessions, she has amassed a great deal of conscious information regarding its possible parameters of response. Such knowledge becomes absorbed into the unconscious memory through a process of embodied experience of the piece which helps Emmerson's "control intimacy" to develop. During a performance situation, she relies on this unconscious source though spontaneous recall, at the same time allowing weight and value to the present moment of sound. Basically her attitude is one of maintaining a balance between memory and instans (the actuality of the moment as represented in this case by the perceived sound material.) An important factor, however, in determining this control is the shifting dramaturgy within the work, where mood changes are initiated by a contrasting live interjection in order to elicit a different electronic response to the previous one. In this light, virtual sounds are indeed unconsciously anticipated on her part, even though the actual moment of performance does not allow for conscious reflection. For example, the glissandi ornamentations that result from live whistling are imagined audibly, in terms of their relative pitch ranges and timbres, prior to their being generated. Her reactions are largely based on a dramatic discourse with the virtual character, in which she engages on the level of sound rather than words, involving expressions of commentary, antagonism, variation, contrast or surprise, to name a few. The extent of these interactions can lead to a third domain where neither sonic element can easily be separated from the other and the combined sound takes on its own direction. In these instances, the instinct is to let the sounds follow their course without assuming personal control of them. Here interactive improvisation can tell us much about the possible dynamic partnership of humans and machines that replaces the domination of autonomous will.

\section{An interactive dramaturgy}

Zaum: Beyond Mind is an interactive piece of sound theater that thrives on its performative instans or present. The flexible medium of interactive electronics, together with interchangeable scenes that involve lighting, choreography and stage set, create an improvisatory environment that necessarily alters with each performance. Several elements are at play here, including audience communication, onomatopoeic language, gesture, eye contact between performers, virtual / live characters and sound. The actor/singer maintains contact with the audience by playing with the meaning of the text using body language, eye contact, gesture and proximity. She is able to re-create this interaction each time by freeing the material from any prestructured local order and tuning in to both the atmosphere and energy field of the performance situation.

There are several levels of dialogues during the piece reflecting different configurations of the relationship between the participants: Caroline, the computer, and Oded. An important moment occurs when the previously mentioned "ghost" voices enter the mix (re-arrangements of Caroline's reading of the text spread over quadrophonic speakers). A certain "distancing” takes place between the virtual voices and her amplified voice, because of their spatial distribution combined with very subtle modifications. They become unpredictable "other" characters moving invisibly through the space from speaker to speaker. The result is an enigmatic internal 
dialogue externalised throughout the performance, as if her own personal space is extended to include the audience. During interactive play, however, a close dialogue is always present between the two or more vocal / instrumental "bodies" breathing while issuing air sounds for example, the one a physical (voice / bandoneon), the other a virtual body. In a sense, the improvisers' body becomes "animated" by the virtual one(s) in a chain of overlapping sound stimuli, so that their borders cross in a constant flow of multiple layers. Ultimately, what is constructed here is a larger momentary "instrument," where slight shifts in instrumental or vocal colour change the resulting sound sequences so that they become multiple "mirrors." The dramatic relationship between the acoustic and electronic is always maintained, however, through an observable connection between herself and the computer, who at times seem to vie for control in their 'play' of sound. This is indicated at key points of sudden stillness and eye contact between Caroline and Oded that frame each improvised section, thus drawing the audience's attention to an important aspect of tension that runs through the work.

Zaum: Beyond Mind is structured in such a way as to allow for improvisational content as well as making musical and dramatic sense. In its present form three large scenes trace the unfolding of sonic and visual material. Within each section, however, the precise duration of interactive material is left open, depending instead on a mutual sense of timing and communication on the part of the performers. Pre-choreographed moments of entrance, gesture and acknowledgment serve a dramatic as well as functional purpose in the overall framework, allowing space for responses to a live audience reaction. Any notated material is not laid down sequentially, serving rather as a palette of possibilities within the passage of one Zaum poem to the next. These go to make up the main body of the first two scenes, while an extended interaction between bandoneon, voice and electronics constitutes the final scene. Ultimately any of the improvisatory interactive moments can be prolonged or shortened according to the performance situation, resulting in a flexibility that recognises, most importantly, the inclusion of the audience in the energy field of a live-generated work.

\section{"Bird-sound with percussive tail""}

Throughout the working process, we also made additional recordings of Caroline improvising with $\mathrm{Pd}$, allowing both of us to reflect on the emerging piece and the interaction between the acoustic and electronic components. In addition to this type of digital sketching (encompassing both sonic material and software components) we sketched musical material in notated form. Being able to reflect on the music we were developing was a crucial element in our ability to develop this piece. While it is common to focus on the spontaneous element in improvisation, often in contrast to the deliberate process of composing at the desk, the role of reflection and monitoring, both in performance and during rehearsal, is somewhat glossed over.

Caroline notated her analyses of the recorded improvisation sessions in order to examine more closely the electronic sound components involved. 
Illustration 4: Score analysis of voice \& electronics. Carolne Wilkins, 2009.

Comparisons between them revealed greater complexity in the patch structure as the collaboration progressed, indicating that important changes were occurring in the overall content of the improvised material. Some key factors mentioned earlier in this article were playing a role in this shift of play: sensitization, control intimacy and gestural nuance. The degree of response and listening on the part of the live improviser had clearly become more finely-tuned towards greater subtleties in the electronics. A sense of local control was more firmly established as she became used 
to monitoring the balance of sound between the two sources, and finally the levels of interaction between computer and performer had been refined to such a degree as to allow for minute gestural nuances of dynamic, speed, timbre, rhythm and pitch to manifest themselves in the sounding result. The electronics were following the melodic contours of the live voice very closely, responding, for example, percussively to a slightly accentuated word or in echo with nuances of pitch to a whispered sound.

These seemingly fine differences actually assume vital importance when it comes to optimising the qualitative nature of an improvised performance. Analysis plays a decisive role in reflecting back the efficacy of the tools and methods that are used to generate material and provides room for their ongoing refinement. Thus the nature of the improvisation changes over time and further delimits the borderline between the live and the virtual. Their sonic combinations become increasingly subtle and complex in identity, creating a third space from which new, transformed identities can emerge.

Thus the seemingly contradictory relationship of analysis to improvisation turns out in fact to be invaluable in its application of conscious processes to a spontaneous act. It offers a comparison with the actors' rigorous training in physical and mental awareness alongside actual performance activities, something that not only prepares her / him to "go through the motions," but also to be fully in the present moment. We should overcome the cerebral and academic connotations of the term "analysis" and recognise that monitoring, both self monitoring and careful attention to other participants in music making, does require analytical skills even if the result is not a formal analysis. Thus understanding the processes involved in playing with such a complex medium as interactive electronics provides a key link to our ability as improvisers to "trust the moment."

\section{Conclusion - "ex tempore” ${ }^{5}$}

Both composition and improvisation are ways of generating musical ideas, and research into musical creativity increasingly shows the commonalities they share (see Sloboda 1985, Lehmann \& Kopiez 2002). This is especially true in the case of contemporary practitioners of interactive electronics, which led Richard Dudas (2010) to coin the term Comprovisation to describe the most common work mode in the field. In describing the role of improvisation in relation to technology, practice, dramaturgy and analysis in our work, we demonstrated how processes traditionally associated with improvisation on the one hand and composition on the other are intermingled. The ability to adapt our working methods and embrace improvisatory as well as compositional strategies was essential to the success of our collaboration.

Aesthetically this has far-reaching consequences for the conception of form in contemporary music practice, owing a great deal not only to a critical use of media technology but also to the consequences of a performative turn in the arts. This concept emphasizes the performance as an event that does not exist on its own, taking place rather in the creative activity of the artist and in the experience of the audience. An early case in point would be Cage's Europeras (1987), whose performances remain unrepeatable each time because of the very nature of their construction, based as they are on chance operations taken from the I-Ching that determine anew the order and combination of the materials. In this sense they are to be understood as events rather than interpretations of a work, and have thus demanded the emergence of a different aesthetic framework based on the performative. In essence, this "turn" refers 
to a radicalisation of the performative aspects of art that concentrates on the here and now of the aesthetic situation, and engenders a mode of self-reflexivity on the part of its participants (Kattenbelt 2010). Digital technology has allowed us to create new temporalities within performance, to explore the past and future in a present moment though simultaneity. We spatialize time, extend it, and intensify it by means of verticality, constantly re-inventing the enormous matrix of the "now" as a "space within time itself.”’(Varela in Hansen 2004: 250)

Our experience conforms to many common assumptions about improvisation practice. A framework - either in the form of received constraints of style or developed through the process - facilitates the ability to improvise. When improvisation develops over a rehearsal process, initial ideas undergo a process of refinement. Listening and reflecting combined with flexibility to adjust to different contexts are needed to sustain a collaborative improvisation. One aspect that is probably different in our case is an imbalance of roles in performance. In most cases of improvising performers there is an egalitarian assumption in the roles played on stage - they usually all contribute in a similar manner during the performance. This is not true in our case - Caroline is clearly the central performer; her presence, visually and aurally, is dynamic and virtuosic and also extends beyond the stage into the electronic sounds. Oded is not performing the computer as a musical instrument on stage, as the links between his limited movements and the resulting sound will not be obvious to the audience ${ }^{6}$. Yet neither do our roles conform to the composer and performer model - Caroline isn't performing a piece composed by Oded. In this regard our piece plays with existing conventions about authorship and its associated hierarchy (and therefore latent power relations) whereby composition is an off-line creativity in opposition to the real-time creative process of performing.

\section{References}

Bay-Cheng, S., Kattenbelt,C., Lavender, A., Nelson, R. (eds) (2010), Mapping Intermediality in Performance. Amsterdam: Amsterdam University Press.

Peter Beyls. Introducing Oscar. In Proc. Int. Computer Music Conference, 1988

Bourdieu, P. (1977), Outline of a theory of practice,Cambridge: Cambridge University Press.

T. Blackwell and M. Young. Self-organised music. Organised Sound, 9(2):123-136, 2004.

Nick Collins (2005) An Automated Event Analysis System with Compositional Applications. Proceedings of the International Computer Music Conference, Barcelona.

Dudas, R. (2010), Comprovisation: The Various Facets of Composed Improvisation within Interactive Performance Systems, Leonardo Music Journal 20, pp. 29-31.

Emmerson, S. (2007), Living Electronic Music, Kent: Ashgate Press.

Garnett, G. (2001), The Aesthetics of Interactive Computer Music, Computer Music Journal 25:1, pp. 21-33.

Hansen, M. (2004), New Philosophy for New Media, Cambridge, MA: MIT Press. 
Harrald, L.A. 2007 Collaborative Music Making with Live Algorithms, Riddell, A. and Thorogood, A. (eds), TRANS: Boundaries / Permeability / Reification.

Proceedings of the Australiasian Computer Music Conference, 19th-21st June, 2007, pp.59-65.

Hayles, N. K. (1999), How we became Posthuman: Virtual Bodies in Cybernetics, Literature, and Informatics, Chicago: Chicago University Press.

Heile, B. (2006), Recent Approaches to Experimental Music theater and Contemporary Opera, Music and Letters, 87:1.

Hsu W. Strategies for managing timbre and interaction in automatic improvisation systems. Leonardo Music Journal 20, pp. 33-39.

Janacek, G. (1996), Zaum: The Transrational poetry of Russian Futurism, San Diego: University of San Diego State University Press.

Jonathan Impett. Interaction, simulation and invention: A model for interactive music. In Artificial Life Models for Music Applications, pages 108-19, Cosenza, Italy, 2001

LaBelle, B. (2006), Background Noise. N.York: Continuum Books.

Lehmann, A. C. \& Kopiez, R. (2002). Revisiting composition and improvisation with a historical perspective. In M. Britta, \& M. Mélen (eds.), Proceedings of the 10th Anniversary Conference of the European Society for the Cognitive Sciences of Music (ESCOM): Musical Creativity, Liège, Belgium, 5-8 April.

Sloboda, J. A. (1985). The musical mind. Oxford: Clarendon.

Van Nort, D. Braasch, J. and Oliveros, P. (2009) A system for musical improvisation combining sonic gesture recognition and genetic algorithms. Proceedings of the $6^{\text {th }}$ SMC 23-25 July Porto.

Vear, C. (2009), Sound theater, unpublished paper presented at T@PRA conference, Plymouth, UK.

Young, M. (2007) NN Music: Improvising with a 'Living' Computer International Computer Music Conference San Francisco 


\section{${ }^{1}$ http://puredata.info/}

${ }^{2}$ Note that both terms and the distinction between them pre-dates electronic music by hundreds of years at least.

${ }^{3}$ David Tudor on improvising with electronics. Composers inside Electronics, Leonardo Music Journal 14 (2004).

${ }^{4}$ A comment by Caroline written on the score page showing voice and electronics analysis.

${ }^{5}$ From the Latin meaning 'out of the time', 'on the spur of the moment',(Oxford Dict.)

${ }^{6}$ An experienced practitioner of live electronics might perceive a degree of sophistication in the underlying programming. 